\title{
The Influence of Cold Pressor Test for Pregnant Blood Pressure
}

\author{
$1^{\text {st }}$ Linda Yanti \\ Midwifery Program Faculty of Health \\ Harapan Bangsa University \\ Central Java, Indonesia \\ lindayanti@uhb.ac.id
}

\author{
$2^{\text {nd }}$ Mariah Ulfah \\ Nusing Departement Faculty of Health \\ Harapan Bangsa University \\ Central Java, Indonesia \\ maydaanzili@gmail.com
}

\begin{abstract}
Internationally the incidence of hypertension in primigravida is around $7-12 \%$, increasing in multiple pregnancy, pregnancy, pregnancy with diabetes mellitus, molahidatidosa pregnancy and in 5-8\% multigravida pregnancy. In Indonesia the estimated incidence of gestational hypertension is around $6-12 \%$ and varies greatly from region to region. Untreated hypertension that causes complications such as stroke, coronary heart disease, diabetes, kidney failure and blindness. Stroke (51\%) and Coronary Heart Disease $\mathbf{4 5 \%}$ ) are the highest causes of death. The purpose of this study was to determine the effect of cold pressor test (CPT) on the blood pressure of pregnant women. This research method is quasi eksperiment with cross sectional design. The population is all
\end{abstract}

\section{INTRODUCTION}

Nearly $50 \%$ of maternal deaths have declined since 1990. Maternal mortality has also declined by about twothirds in Asia and Africa. In developed countries maternal mortality is lower than in developing countries, but only some receive quality health services.[1] Even though reducing maternal mortality is a deep target on sustainable development goals.[2]

Hypertension is a condition where systolic blood pressure is more than $120 \mathrm{mmHg}$ and diastolic pressure is more than $80 \mathrm{mmHg}$.[3] Hypertension is an increase in blood pressure in the arteries continuously. Hypertension is a systolic pressure of more than $160 \mathrm{mmHg}$ or more or a diastolic pressure of $95 \mathrm{mmHg}$ or more.[4]

Internationally the incidence of pregnancy hypertension in primigravida is around $7-12 \%$, pregnant women who visit the Kembaran 1 Community Health Center. Large samples in this study were calculated using the formula obtained obtained 80. Primary data in the form of blood pressure before and after Cold Pressor Test. Univariate analysis is to analyze the pressure before and after supporting the cold pressor test Bivariate analysis in this study to test the effect of the cold pressor test on the blood of pregnant women using a simple test pair test. The result is There are differences in the blood pressure of pregnant women given before and after the cold press test

Keywords: cold pressor test, pregnancy blood pressure

increasing in multiple pregnancy, hydramnios, pregnancy with diabetes mellitus, molahidatidosa pregnancy and in multigravida 5-8\%. In Indonesia the estimated incidence of gestational hypertension is around $6-12 \%$ and varies greatly from region to region. Hypertension that does not get good treatment causes complications such as stroke, coronary heart disease, diabetes, kidney failure and blindness. Stroke $(51 \%)$ and Coronary Heart Disease $(45 \%)$ are the highest causes of death. Target organ damage due to complications of hypertension will depend on the magnitude of the increase in blood pressure and the duration of the condition of the blood pressure that is undiagnosed and untreated. The organs of the body that are targeted include the brain, eyes, heart, kidneys, and can also affect the peripheral arteries themselves. [4]

Pregnancy hypertension disorders are a cause of maternal death, accounting for $18 \%$ of all maternal 
deaths in the world or 62,000 to 77,000 deaths each year [6][7],[8] Hypertension in pregnancy results in the death of about one in 1700 to one in 2100 based on global data.[9] There are broad categories for the classification of hypertension in pregnancy. There are broad categories for the classification of hypertension in pregnancy are gestational hypertension (without proteinuria), preeclampsia, ie hypertension with proteinuria and chronic hypertension or essential hypertension is hypertension that was present before pregnancy or without superimposed preeclampsia.[10] Morbidity mostly occurs between pregnancies due to preeclampsia or eclampsia and every woman who dies about 20 others suffer from severe morbidity.[6] Hypertension in pregnancy is very closely related to pre-eclampsia, eclampsia and HELLP syndrome up to $10 \%$ of pregnancies [6], [11] omen with hypertensive disorders of pregnancy have an increased risk of post-pregnancy hypertension, ischemic heart disease, and stroke.[12]

Maternal Mortality Rate In Banyumas District there are 14 per $100,000 \mathrm{KH}, 60 \%$ of maternal deaths occur during childbirth, $26.32 \%$ occur during pregnancy and $13.68 \%$ occur at delivery. The maternal mortality rate is due to metabolic disorders $(0.87 \%)$, infections $(4.34 \%)$, circulatory disorders $(12.36 \%)$, bleeding $(30.37 \%)$, hypertension in pregnancy $(32,97 \%)$ and others $(19,09 \%)$.[13]

Diagnosis of hypertension if at pressure of $140 / 90 \mathrm{mmHg}$ or more on examination with a distance of 6 hours. Causes include genetic, environmental, hyperactivity of the in sympathetic nerves, angiotensin renin, defection in $\mathrm{Na}$ excretion, increase in $\mathrm{Na}$, and intracellular $\mathrm{Ca}$ and factors that increase risk such as obesity, alcohol, smoking, and polycythaemia. Preeclampsia is pregnancy induced hypertension accompanied by a significant increase in proteinuria. In pregnancy, protein excretion can be increased but total protein up to $300 \mathrm{mg}$ per 24 hours is normal.

Detection of hypertension in pregnant women is done with a cold pressor test (CPT) and regular checks by health workers. Studies show that sympathetic nerves play an important role in hypertension due to increased sympathetic nerve activity. Sympathetic activity was tested using a cold pressor test. CPT is done by measuring the blood pressure response to cold stimuli given during the experiment. This test is used to detect hypertension early. Hyperreaction response during CPT can predict the risk of hypertension.[14] Increased blood pressure during CPT can be caused by several factors, including increased sympathetic nervous system activity, vasoconstriction, and feelings of pain during immersion in ice water. Blood pressure is influenced by two factors, namely blood flow and peripheral vascular pressure. The body's blood flow is affected by cardiac output, heart rate, and blood volume itself. Cold stimulation of the hands dipped in ice water creates a stimulus to the heart's sympathetic nerves which causes vasocontraction of blood vessels. Vascular vasocontraction causes an increase in blood pressure values.[15]

\section{METHODS}

This research is a quantitative study. This type of research is a quasi experimental design with one group pretest and post-test, which means that researchers can test changes that occur before and after treatment is given.[16]

This research was conducted at the Kembaran 1 Public Health Center with a population of all pregnant women and the sample size calculated by the Solvin formula obtained 80 respondents as pregnant women. The inclusion criteria in this study were pregnant women I, II, III, IV with a maximum age of 40 years. The technique of taking the sample was accidental sampling. Data was analyzed by using paired sample t-test.

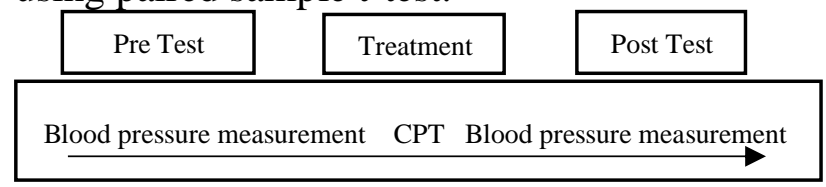

Figure.1 Research Design Design

\section{FINDINGS AND DISCCUSION}

Blood pressure before and after the administration of cold pressor test intervention at the Kembaran 1 
Public Health Centre is presented in the following table:

Table.1 Systolic blood pressure before and after the administration of cold pressor test intervention at the Kembaran 1 Community Health Center $(n=80)$

\begin{tabular}{|c|c|c|c|c|}
\hline \multirow{2}{*}{$\begin{array}{c}\text { Sistole } \\
\text { Blood } \\
\text { Pressure }\end{array}$} & \multicolumn{2}{|c|}{ Pre } & \multicolumn{2}{|c|}{ Post } \\
\hline & $f$ & $\%$ & $f$ & $\%$ \\
\hline 90 & 6 & 7.5 & 1 & 1.25 \\
\hline 96 & 1 & 1.25 & - & - \\
\hline 97 & 1 & 1.25 & - & - \\
\hline 100 & 31 & 38.75 & - & - \\
\hline 101 & - & - & 1 & 1.25 \\
\hline 103 & - & - & 1 & 1.25 \\
\hline 104 & 1 & 1.25 & - & - \\
\hline 108 & - & - & 1 & 1.25 \\
\hline 109 & 1 & 1.25 & 1 & 1.25 \\
\hline 110 & 21 & 26.25 & 9 & 11.25 \\
\hline 112 & 2 & 2.5 & 3 & 3.75 \\
\hline 113 & 1 & 1.25 & 1 & 1.25 \\
\hline 114 & 1 & 1.25 & - & - \\
\hline 116 & 1 & 1.25 & - & - \\
\hline 117 & 1 & 1.25 & 1 & 1.25 \\
\hline 120 & 11 & 13.75 & 25 & 31.25 \\
\hline 122 & - & - & 1 & 1.25 \\
\hline 125 & - & - & 9 & 11.25 \\
\hline 126 & - & - & 1 & 1.25 \\
\hline 128 & - & - & 1 & 1.25 \\
\hline 130 & - & - & 13 & 16.25 \\
\hline 134 & 1 & 1.25 & - & - \\
\hline 135 & - & - & 7 & 8.75 \\
\hline 140 & - & - & 1 & 1.25 \\
\hline 145 & - & - & 3 & 3.75 \\
\hline Total & 80 & 100 & 80 & 100 \\
\hline
\end{tabular}

Table.2 Diastolic blood pressure before and after the administration of cold pressor test intervention at the Kembaran 1 Community Health Center $(n=80)$

\begin{tabular}{ccccc} 
Diastole & \multicolumn{2}{c}{ Pre } & \multicolumn{2}{c}{ Post } \\
\cline { 2 - 5 } $\begin{array}{c}\text { Blood } \\
\text { Pressure }\end{array}$ & $f$ & $\%$ & $f$ & $\%$ \\
\hline 59 & - & - & 1 & 1,25 \\
\hline 60 & 1 & 1,25 & 1 & 1,25 \\
\hline 65 & 1 & 1,25 & - & - \\
\hline
\end{tabular}

\begin{tabular}{ccccc}
\hline 66 & 1 & 1,25 & - & - \\
\hline 70 & 30 & 37.5 & 5 & 6.25 \\
\hline 71 & 1 & 1,25 & - & - \\
72 & 1 & 1,25 & 1 & 1,25 \\
\hline 73 & 1 & 1,25 & - & - \\
\hline 74 & - & - & 3 & 3,75 \\
\hline 75 & 1 & 1,25 & - & - \\
\hline 76 & - & - & 1 & 1,25 \\
\hline 77 & 1 & 1,25 & - & - \\
\hline 80 & 27 & 33.75 & 12 & 15 \\
\hline 81 & 2 & 2.5 & 2 & 2,5 \\
\hline 84 & 2 & 2.5 & 3 & 3,75 \\
\hline 85 & 1 & 1,25 & 1 & 1,25 \\
\hline 90 & 10 & 12.5 & 8 & 10 \\
\hline 95 & - & - & 1 & 1,25 \\
\hline 100 & - & - & 31 & 38,75 \\
\hline 110 & - & - & 5 & 6,25 \\
\hline 115 & - & - & 5 & 6,25 \\
\hline Total & 80 & 100 & 80 & 100
\end{tabular}

Table. 3 Cold pressor test affects the blood pressure of pregnant women $(n=80)$

\begin{tabular}{cccccc}
\hline $\begin{array}{c}\text { Tekanan } \\
\text { Darah }\end{array}$ & Mean & $\begin{array}{c}\text { Mean } \\
\text { Dif }\end{array}$ & $\mathrm{t}$ & Sig \\
\cline { 1 - 3 } Sistole & Pre & 106,18 & - & - & 0,000 \\
\cline { 2 - 5 } & Post & 122,23 & 16.05 & 11.17 & \\
\cline { 1 - 5 } Diastole & Pre & 76,68 & - & - & 0,000 \\
\cline { 2 - 5 } & Post & 91,73 & 15.50 & 10.90 & \\
\hline
\end{tabular}

Based on table1 it can be seen that the blood pressure of systole experienced by pregnant women before being given an intervention are all in normal conditions which is $90-134(100 \%)$. Most of the systolic pressure is 100 as many as 31 pregnant women (38.75). Whereas after being given the intervention most are still in normal numbers which is 120 as many as 25 pregnant women (31.25\%) although the average lifetime in the normal category but the majority of pregnant women experience hypereactor (blood pressure rises $>20 \mathrm{mmHg}$ ).

Based on table 2 it can be seen that the diastolic blood pressure experienced by pregnant women before being given an intervention are all in normal conditions which is $60-90(100 \%)$. The majority of 
diastolic blood pressure is 70 as many as 30 pregnant women $(37.5 \%)$. Whereas after being given the intervention most of them increased to 100 as many as 31 pregnant women $(38.75 \%)$ and most pregnant women experienced hypereactor (blood pressure rises $>15 \mathrm{mmHg}$ ).

In table 3 it can be seen that the average systolic blood pressure before the cold pressor test was $106.18 \mathrm{mmHg}$ and the average blood pressure after the cold pressor test was $122.23 \mathrm{mmHg}$. Whereas for the average blood pressure diastole before being given a cold pressor test was $76.68 \mathrm{mmHg}$ and the average blood pressure after being given a cold pressor test was 91, $73 \mathrm{mmHg}$. Based on data analysis, the significance value in this study was 0,000 , which means that there were significant differences in the blood pressure of pregnant women before and after the cold pressor test was given, or in other words there was an influence on the administration of cold pressor tests on the blood pressure of pregnant women. In this study the difference between the average systole blood pressure before and after the administration of the cold pressor test was -16.05 and the difference between the differences between -18.90 to -13.19 . While the difference between the average blood pressure of diastole before and after administration of the cold pressor test is -15.50 and the difference is between -17.79 to -12.30 .

New information shows that the first year of postpartum is the most important thing. A study in Indonesia reported a fivefold increase in cases of hypertension in post partum mothers in the first five years after experiencing pregnancy with preeclampsia/ eclampsia. Other findings show that $2545 \%$ of women with hypertensive disorders of pregnancy within five years after giving birth to the risk of experiencing hypertension.[17] An increased risk of hypertension arises after pregnancy which is influenced by the presence of hypertension. The existence of pregnancy disorders and how the risk changes with increasing time since pregnancy is still unclear the cause. Understanding the risk patterns of hypertension after experiencing hypertensive disorders of pregnancy will allow doctors to plan follow-up and post-natal diagnosis as early as possible.[18]

The possibility of women diagnosed with hypertension is no different from women with or without a history of pregnancy hypertension disorders. Hypertension was diagnosed within one year of post partum and a mixture of hypertension before pregnancy that was not detected and a new attack of hypertension. From a clinical perspective, whether hypertension is detected at post partum, before pregnancy or is a continuation of pregnancy hypertension disorders is not very important. Hypertension disorders before pregnancy have a much higher level of hypertension. Therefore, every woman is very important to conduct an examination in order to detect early the presence of hypertension or the possibility of hypertension in the future.[19], [20], [21]

Cold Pressor test is done by measuring the blood pressure response to cold stimuli given during the experiment. This test is used to detect hypertension early. Hyperreaction response during CPT can predict the risk of hypertension in the future.[22] When afferent sensory nerve cold testor is carried out it triggers systemic sympathetic activation which causes marked vasoconstriction. The result is an increased pulse pressure (normal is $40 \mathrm{mmHg}$ ), due to the release of catecholamines. This increased pressure fills the ventricles to a higher level, but the stroke volume decreases due to increased afterload. An increase in blood pressure during the cold pressor test can be caused by several factors, including an increase in sympathetic nervous system activity, vasoconstriction, and a feeling of pain during soaking in ice water with a temperature of $1-18^{\circ} \mathrm{c}$. Blood pressure is influenced by two factors, namely blood flow and peripheral vascular pressure. the body's blood flow is affected by cardiac output, heart rate, and blood volume itself. Cold stimulation of the hands dipped in ice water creates a stimulus to the heart's sympathetic nerves which causes vasocontraction of blood vessels. Vasocontraction of blood vessels causes increased blood pressure values. In theory, systole blood pressure and diastole increase when the hands are put into ice water, this 
is in accordance with the mechanism of the human body, ie when the body is in a relatively low temperature condition the blood vessels will constrict (vasocontraction). If the cooling systolic pressure rises greater than $20 \mathrm{~mm} / \mathrm{hg}$ and diastolic pressure is more than $15 \mathrm{~mm} / \mathrm{hg}$ from the basal pressure, it is included in the hyperreactor group that has the potential for hypertension in the future, if the increase in blood pressure is less than that number then the hyporeactor is an increase in which is still considered normal and the possibility for future hypertension is small.[23] Cold Pressor test is associated with an increase in endothelin levels in the blood. Stimuli that release these substances cause strong vasoconstriction in blood vessels.[24]

\section{IMPLICATION FOR PRACTICE}

The results of the study are very important for making standard operational procedures on how to predict hypertension in early pregnancy. However, to implement a cold pressor test requires commitment from the health workers in charge.

\section{STRENGTH AND LIMITATION}

This research has strengths and limitations. The strength of this research lies in the administration of cold pressor tests (CPT) to pregnant women and the limitation of this study is that the observations made do not reach the next pregnancy. It should be observed for hypertension in the next pregnancy. Then the number of respondents is also better plus not only on 80 pregnant women.

\section{CONCLUSION}

There are differences in the blood pressure of pregnant women given before and after the cold press test

\section{REFERENCES}

[1] Duncan, "Sustainable Devlopment Goals," Japanese Soc. Biofeedback Res., vol. 19, pp. 463-466, 1992.
[2] I. Briefing and S. Urban, "The Sustainable Development Goals (SDGs), the centerpiece of the 2030 Agenda for Sustainable Development, were adopted by the United Nations Sustainable Development Summit in September 2015. This briefing sheet explains the formation of the SDGs and exami," no. 01, pp. 1-4, 2015.

[3] Muttaqin A, Asuhan Keperawatan Klien Dengan Gangguan Sistem Kardiovaskular. Jakarta: Salemba Medika, 2012.

[4] Kemenkes.RI, "Infodatin Hipertensi," Infodatin, no. Hipertensi, pp. 1-7, 2014.

[5] V. L. P. Khan KS, Wojdyla D, Say L, Gülmezoglu AM, "WHO analysis of causes of maternal death: a systematic review," Pubmed, vol. 367 (9516), no. 1 April, pp. 1066-1074, 2006.

[6] E. Abalos, C. Cuesta, A. L. Grosso, D. Chou, and L. Say, "Global and regional estimates of preeclampsia and eclampsia: A systematic review," Eur. J. Obstet. Gynecol. Reprod. Biol., vol. 170, no. 1, pp. 1-7, 2013.

[7] World Fertility Data. United Nation Population Division, "World Contraceptive Use 2019," Dep. Econ. Soc. Aff., 2019.

[8] Wold Fertility Data, "World Fertility Data," United Nation Popul. Div. Fertil. Fam. Plan. Sect., 2008.

[9] WHO, UNICEF, UNFPA, and World Bank, "Maternal mortality trend analysis 19902010," 2012.

[10] E. J. Roccella, "Report of the National High Blood Pressure Education Program Working Group on High Blood Pressure in Pregnancy," Am. J. Obstet. Gynecol., vol. 183, no. 1, pp. 1-22, 2000.

[11] O. Dssursuldwh, S. Fduh, Z. Revhuydwlrq, S. Rxwfrphv, V. P. Pruelglw, and D. Q. G. Pru, "Hypertension in Pregnancy," vol. 122, no. 5, pp. 1122-1131, 2013.

[12] L. Bellamy, J. P. Casas, A. D. Hingorani, and D. J. Williams, "Pre-eclampsia and risk of cardiovascular disease and cancer in later life: Systematic review and meta-analysis," $B r$. 
Med. J., vol. 335, no. 7627, pp. 974-977, 2007.

[13] BKKBN, Sdki 2017. 2017.

[14] S. Hada, S. Amatya, and R. K. Shrestha, "Cold pressor test in borderline hypertensive university students," Kathmandu Univ. Med. J., vol. 14, no. 56, pp. 337-341, 2016.

[15] D. U. Silverthorn and J. Michael, "Cold stress and the cold pressor test," Adv. Physiol. Educ., vol. 37, no. 1, pp. 93-96, 2013.

[16] Arikunto, Prosedur Penelitian Pendekatan Proses. Jakarta: Rineka Cipta, 2010.

[17] J. H. W. Veerbeek et al., "Cardiovascular disease risk factors after early-onset preeclampsia, late-onset preeclampsia, and pregnancy-induced hypertension," Hypertension, vol. 65, no. 3, pp. 600-606, 2015.

[18] I. Behrens et al., "Risk of post-pregnancy hypertension in women with a history of hypertensive disorders of pregnancy: Nationwide cohort study," BMJ, vol. 358, 2017.

[19] Davies, "PHYSICIANS' KNOWLEDGE OF FUTURE VASCULAR DISEASE IN WOMEN WITH PREECLAMPSIA," Bone, vol. 23, no. 1, pp. 1-7, 2008.

[20] M. B. Heidrich, D. Wenzel, C. S. von Kaisenberg, C. Schippert, and F. M. von Versen-Höynck, "Preeclampsia and longterm risk of cardiovascular disease: What do obstetrician-gynecologists know?," $B M C$ Pregnancy Childbirth, vol. 13, pp. 2-7, 2013.

[21] G. S. M. P. Susan E.Mac Donald MD MHSc, Mark Walker MD MSc, Heather Ramshaw BSc, Marshal lGodwin MD MSc, Xi-kuan Chen MD PhD, "MacDonald SE, Walker M, Ramshaw H, Godwin M, Chen XK, Smith G. Hypertensive disorders of pregnancy and long-term risk of hypertension: what do Ontario prenatal care providers know, and what do they communicate?," J. Obstet. Gynecol. Canada, vol. 29, no. September, pp. 705-710, 2007.
[22] P. D. Dilipkumar, N. Dikshit, and D. Parchwani, "Blood Pressure Responsiveness to the Cold Pressor Test in Normotensive Young Adults," vol. 6, pp. 35-42, 2017.

[23] R. G. Victor, W. N. Leimbach, D. R. Seals, B. Gunnar Walljn, and A. L. Mark, "Effects of the cold pressor test on muscle sympathetic nerve activity in humans," Hypertension, vol. 9, no. 5, pp. 429-436, 1987.

[24] I. Korhonen, "Blood pressure and heart rate responses in men exposed to arm and leg cold pressor tests and whole-body cold exposure.," Int. J. Circumpolar Health, vol. 65, no. 2, pp. 178-184, 2006. 